University of Nebraska - Lincoln

DigitalCommons@University of Nebraska - Lincoln

Contemporary Issues in Educational Leadership Educational Administration, Department of

$1-3-2020$

Paths to the Baccalaureate at a Hispanic-Serving Institution: The Lived Experiences of Latinos who Entered Higher Education at the Community College

Brent D. Cejda

Follow this and additional works at: https://digitalcommons.unl.edu/ciel

Part of the Bilingual, Multilingual, and Multicultural Education Commons, Educational Administration and Supervision Commons, Educational Leadership Commons, and the Higher Education Commons

This Article is brought to you for free and open access by the Educational Administration, Department of at DigitalCommons@University of Nebraska - Lincoln. It has been accepted for inclusion in Contemporary Issues in Educational Leadership by an authorized administrator of DigitalCommons@University of Nebraska - Lincoln. 


\title{
Paths to the Baccalaureate at a Hispanic- Serving Institution: The Lived Experiences of Latinos who Entered Higher Education at the Community College ${ }^{1}$
}

\author{
Brent D. Cejda, Ph.D. \\ College of Education and Human Sciences \\ University of Nebraska-Lincoln
}

\begin{abstract}
The U.S. Census indicates that Hispanic participation in postsecondary education tripled between 1996 and 2016. If the traditional outcome measure of the sixyear graduation rate is used, however, increased participation has not resulted in an increased number of Latinos who complete a bachelor's degree. Further, typical examinations of baccalaureate completion have focused on the starting point-beginning at a community college or beginning at a four-year college or university and compare percentages of completion by race or ethnicity. Findings of such studies point to the disparity in bachelor's degree completion rates
\end{abstract}

1. The term "Hispanic" was adopted by the U.S. Census in the 1980 os and is a broad term that is meant to encompass people who are from Spanish-speaking countries. In this paper I use the term Latina/o or Latinos as plural to identify the participants in the study and do not use Latinx as the only gender markers available for participant identification were male and female. Hispanic-Serving Institution is a designation by the Department of Education that identifies eligible institutions according to the enrollment percentage of undergraduate students from the preceding year. I use that designation in referencing the institution from which the participants graduated. In referencing and citing literature, I use the term used by the respective sources. 
between Latinos and other racial and ethnic groups and that the disparity is even greater among individuals who begin postsecondary education at the community college. This paper follows an anti-deficit approach to gain a greater understanding of the complexities of baccalaureate completion of Latina/o students beyond the common measure of a six-year timeframe and the simplified starting point of the community college. Learning from the success of the participants may provide insight helpful to educational leaders who seek to provide access and facilitate the success of Latino students.

$\mathrm{T}$ HE U.S. Census indicates that the Hispanic population grew exponentially during the first decade of the $21^{\text {st }}$ century and is now the largest ethnic or racial minority in the United States. In addition to increases in the population, greater percentages of Hispanic youth are completing high school and enrolling in postsecondary education. Between 1996 and 2016 the college enrollment of Hispanics tripled (Bauman, 2017).

The community college has been described as the pipeline for Hispanics in higher education (Rendon \& Nora, 1989; Laden, 1992, 2001). Between 2006 and 2011 almost 600,000 additional Hispanics enrolled in community colleges and in 2011 42.9\% of all Hispanic enrollment in higher education was in community colleges (Bauman, 2017). Obviously, the community college significantly contributed to increased Latino participation in postsecondary education. While participation rates have increased, disparities in baccalaureate outcomes continue between Latino and white college students. In $2015,15.5 \%$ of Hispanics over the age of 25 had earned a baccalaureate degree, compared to $36.2 \%$ of non-Hispanic whites (Ryan \& Bauman, 2016). Before the 2006-2011 growth in enrollments, particular concern was raised regarding the limited numbers of Latino students who successfully transfer from community colleges to four-year institutions and complete the baccalaureate degree.

Among the Hispanic students in the Beginning Postsecondary Students Longitudinal Study who attended a community college, slightly less than $25 \%$ indicated the intent to transfer to a four-year institution and earn a bachelor's degree. Six years after enrolling in community colleges, only 
$6 \%$ of Hispanic students had been awarded the baccalaureate (Hoachlander, Sikora, Horn, \& Carroll, 2003). Using data from the National Education Longitudinal Study of 1988, Fry (2004) found that, among students who entered the community college as "minimally qualified" for postsecondary education, $16 \%$ of whites completed a bachelor's degree compared to only $7 \%$ of Latinos. Swail, Cabrera, and Lee (2004) found a baccalaureate completion ratio of almost 2:1 between whites and Latinos who entered higher education at a community college. A decade later this disparity has not changed. Among students who started at a community college in Fall 2010 and then continued their education at a four-year public institution, slightly less than 10\% of Hispanic students had finished a bachelor's degree after six years compared to $20 \%$ of white students (Shapiro et al., 2017).

There is a body of literature that has examined the reasons fewer numbers of Latino students complete the baccalaureate. The National Center for Education Statistics (2002) identified seven characteristics that negatively impact baccalaureate completion: delayed postsecondary enrollment, part-time enrollment, not having a regular high school diploma, working full-time, being financially independent or from low-income families, having children or dependents, and being a single parent. Although these characteristics apply to all postsecondary students, Fry (2003) stressed that Hispanic undergraduates are more likely to experience these risk factors. Subsequent research indicates that these risk factors are prevalent among Latinos attending community colleges and Hispanic Serving Institutions (Crisp \& Nora, 2010; Nuñez, Sparks, \& Hernandez, 2011; Sáenz, Mayo, Miller, \& Rodriguez, 2015).

In their examination of Latino college attendance and degree attainment, Swail et al. (2004) found that Latinos were more likely to have been retained at a grade level for an additional year, attended more than two high schools, completed lower-level mathematics courses, earned a grade of $\mathrm{C}$ or lower in at least one course, or had dropped out. A low-level of math ability has been identified as one reason that Latinos are not eligible for admission to the California State University or University of California systems, resulting in the majority of Latino students entering higher education in the community college sector (Contreras, 2015). Swail et al. further identified that family characteristics such as parents who did not graduate from high school or have postsecondary experience and having a sibling who dropped 
out as additional factors contributing to lower degree completion rates. Sáenz, Garciá-Louis, Drake, \& Guida (2018) identified parents with less than a high school degree as a challenge to the academic success of Latino males attending a community college. The existence of these factors are posited as contributing to fewer numbers of Latinos completing the baccalaureate.

Arbona and Nora (2007) took a slightly different approach and examined factors that significantly increased the likelihood of Hispanics obtaining a bachelor's degree. In addition to factors already referenced, they found that continuous enrollment while attending college significantly increased the probability of completing a bachelor's degree among Hispanics regardless of whether they began postsecondary education at a two- or four-year institution. Among Hispanics who initially enrolled at a community college, aspiring to earn a college degree during the $10^{\text {th }}$ grade and completing a rigorous high school curriculum significantly increase the likelihood of degree completion.

\section{Purpose}

Harper (2010) challenged researchers to move beyond questions that asked "why not" when considering lower levels of success to questions that focused on "how did" in proposing an anti-deficit framework for research on student outcomes. Abrica (2018) pointed out that traditional outcome measures may reinforce previous narratives of success and/or failure. What is lacking in the literature are studies focused on developing a more in-depth understanding of the paths of Latinos who have been successful and completed the baccalaureate degree. In a review of research, Reyes and Nora (2012) stressed that "no studies which we have found seem to examine Latino first-generation college students' persistence through degree completion specifically" (p. 27). My review of the literature found one study (Marrón \& Luna, 2019) that examined factors that motivated Latinas completing a bachelor's degree, but did not broadly consider strategies that addressed challenges and barriers. The following question will guide this study: Beyond the type of postsecondary institution they initially enroll in, are there recurring pathways to the baccalaureate degree and how did Latino students navigate these pathways? 


\section{Conceptual Framework}

Path dependence was originally an economic theory but has become a popular phrase, used broadly to mean that history matters (Pierson, 2004). This wider use of the term has been criticized as trivial (Page, 2006). Heller (2006), however, points out that path dependence has been useful in examining and understanding non-optimal outcomes. I view the lower percentage of baccalaureate attainment among Latinos who enter postsecondary education at the community college as a non-optimal outcome and, thus, path dependence as an appropriate conceptual framework.

Moreover, several studies have found that history does matter. As the American higher education system has operated, an overwhelming percentage of Latinos have enrolled in community colleges and non-selective four-year institutions and their baccalaureate completion rates lag significantly behind other racial and ethnic groups (Arbona \& Nora, 2007; Fry, 2002, 2004; Lee, Mackie-Lewis, \& Marks, 1993; Shapiro et al., 2017; Swail, Cabrera, Lee, \&Williams, 2005). The incorporation of a path dependency framework serves three purposes. First, it considers the existence of more comprehensive paths. I hypothesize that the experiences of Latinos who have completed the baccalaureate can be described in greater detail than simply by the type of institution where they began postsecondary study. Second, even the critics of path dependency agree that different histories happen. Path dependency helps explain how and why some Latinos complete a bachelor's degree and others do not.

Finally, it would seem that there are three options for improving the baccalaureate completion rates of Latinos. Fry (2004) and others have stressed the importance of dramatically increasing the numbers of Latinos who attend more selective institutions of higher education as the means to increase baccalaureate attainment rates. Oseguera, Locks, \& Vega (2009) stressed the importance of developing institutional practices that improve the retention, and thus graduation rates, of Latinos. A third option would be to learn from the success of those who have earned the bachelor's degree and consider alternative outcome measures suggested by paths that are, and for many reasons, may remain common. 


\section{Method}

\section{Research Design}

To examine whether there were multiple paths to the baccalaureate that began at the community college, I employed a phenomenological approach (Merriam, 2002). This approach focuses on the phenomena of completing a baccalaureate degree with the analysis based on the perspective of the Latina/o graduates who experienced the phenomenon. To accomplish this purpose, I conducted a series of face-to-face interviews, the primary method of data collection used in the phenomenological framework (Merriam, 2002). I followed a semi-structured interview protocol (Bogdan \& Biklen, 2003) to make sure that the same information was gathered from each participant.

\section{Procedures}

Interviews were conducted at a public, four-year Hispanic-Serving Institution (HSU). HSU has an unduplicated headcount of 14,450 undergraduates. Undergraduate Hispanic enrollment at the institution is $82 \%$ of the total student body and approximately $60 \%$ of the students are women. The vast majority of HSU students are from low socio-economic backgrounds, with $84 \%$ of the full-time, first-time undergraduate students receiving federal grants.

After approval to conduct the study was received from an institutional review board, the Alumni and Registrar offices at HSU facilitated the recruitment of participants. To protect the anonymity of the participants, the HSU offices identified potential participants through purposeful sampling, based on the criteria of ethnic identification, baccalaureate completion within the past three years, and postsecondary participation beginning at a community college. Potential participants were sent an email explaining the study, with a brief demographic survey. Surveys were received from 32 potential participants who met the criteria of the study. A follow-up email was sent by the Alumni Office to these individuals, inviting them to contact me via email or telephone to schedule an interview. Of the 32 potential participants, 29 scheduled an interview session and 26 individuals completed an interview. Of the 26 participants, 11 identified as male and 15 identified as female. 
Nine (34\%) of the participants were 24 years of age or younger and 17 were 25 years of age or older at the time they completed the bachelor's degree. Each of these individuals identified themselves as from Hispanic, Latino, or Spanish heritage on their graduation application and had been awarded a baccalaureate degree in the previous three years from HSU. Each had entered postsecondary education at a community college and had completed at least 15 community college credit hours in meeting the requirements for the bachelor's degree.

I traveled to the HSU campus to gather data. Interviews were conducted in private locations on the campus and averaged approximately one hour in length. Two separate permissions were obtained from the participants; one to conduct the interview and the other to audio record the interview. Participants selected pseudonyms to further protect their confidentiality.

The primary purpose of this study was to examine whether there were identifiable paths followed by baccalaureate graduates who began postsecondary education at a community college beyond simply identifying the community college as the starting point. A secondary purpose was to search for possible explanations of "how" the graduates navigated the path(s). A semi-structured interview guide was divided into three sections to examine:

- Personal and family characteristics that might influence the path to and likelihood of completing the baccalaureate;

- Educational characteristics while pursuing the baccalaureate

- Whether the person started postsecondary education immediately after completing high school or the GED,

- Whether the person began postsecondary education with the intent of earning a bachelor's degree,

- The type, number, and sequence of the institution(s) attended, and

- Enrollment patterns (full- or part-time);

- The perceptions of the participants as to how they persisted and ultimately completed a bachelor's degree.

\section{Analyses}

The interviews were transcribed by a transcription service and data analyses occurred in two stages. In the first stage, I incorporated a modified analytic induction model (Bogdan \& Biklen, 2003) to identify the various paths to 
the baccalaureate. The purpose of using an analytic induction model was to develop descriptions that included all of the instances of the phenomenon, the paths of all 26 participants in the study. I began this stage with the broad categorization of one path, starting at a community college and based on common experiences ended with four paths.

In the second stage, I reviewed transcripts and field notes made after each interview through an interpretative approach (Berg, 2004), attempting to capture the essence of the participants' descriptions of their personal and family characteristics and their experiences while pursuing the bachelor's degree. In searching for greater clarification, I drew on the existing literature on Latina/o college attendance and degree attainment in an attempt to identify explanations as to how these participants had been successful in the pursuit of the baccalaureate. The interpretative approach allowed for a more comprehensive explanation of the lived experiences of the participants than would have been achieved by simply sorting or coding discreet words or phrases.

An independent reviewer examined my analysis of each of the identified paths, as well as my interpretation of the lived experiences of the participants with no major discrepancies emerging. As a final step, each participant received a summary of the path I identified for them as well as my overall interpretation of the lived experiences as a form of member checking. Each individual was asked to reply as to whether they agreed with the placement on the respective path and whether I had captured the essence of the lived experience. Seventeen of the 26 participants responded and all indicated agreement with their path placement. Two of the 17 added additional comments about the lived experience but did not disagree with any points of my interpretation.

\section{Paths to the Baccalaureate Beginning at a Community College}

Four paths emerged among the Latinos who completed the baccalaureate and began postsecondary education at a community college. Table $\mathbf{1}$ displays the identified paths, the number of participants that followed each respective path. The narrative following the table provides a detailed description of the paths. 
Table 1. Community College Paths $(n=26)$

\begin{tabular}{lrc} 
Path & Number & Percent \\
\hline Career & 11 & 42 \\
Heating Up & 7 & 27 \\
Traditional & 6 & 23 \\
Dual enrollment & 2 & 8 \\
\hline
\end{tabular}

\section{The career path}

Participants who followed the career path pursued postsecondary education for economic gain and completed a number of courses, a certificate or an associate's degree at a community college in a career area (e.g., hvac, nursing, auto repair, computer technology). None of the individuals in the career path indicated that they enrolled at the community college with the goal of completing a bachelor's degree. Fred, a career path participant explained:

I didn't know much about college, but was told by my high school auto teacher that I would be a good mechanic and could make more money if I completed the community college program. So, that is why I enrolled at the community college-to make more money.

Fred referenced a high school teacher as an influence in his decision to enroll at the community college. Each of the career path individuals referenced a high school teacher or a supervisor or coworker at a part-time or summer job as influencing their decision to pursue postsecondary education.

After completing a credential or degree, the career path participant "stopped out" of postsecondary education and entered the workforce. Career path individuals in this study worked between 2 and 7 years and then returned to postsecondary education to pursue a bachelor's degree. Some participants returned to higher education in a field different from their original career area. Becky completed an associate's degree in computer technology and shared: 
I made good money working in computers, but after a number of years it had become too routine, the same thing day after day. I thought, is this the rest of my life ... wasn't there more? Another worker on my team suggested that I check into going back to school ... I was surprised about how many hours from the associate degree counted. (after probing question) I majored in business after I returned.

Five of the career path participants continued in the same field of study, such as completing an associate degree in nursing and later returning to earn a BSN degree. As with Becky, 9 of the 11 career path participants identified encouragement from individuals as a reason they returned to pursue the baccalaureate. Immediate supervisors and coworkers were most often identified as individuals who influenced the decision to return, followed by spouses/significant others and then members of extended families.

Seven of the career path participants returned to a community college for assistance in reentering postsecondary education, contacting faculty members, advisors, and career and transfer staff. Six of these found they could complete additional requirements at the community college that would transfer to HSU and all six took the maximum community college credits possible prior to transfer.

Eight of the career path participants stressed that their experiences at the community college gave them the confidence to return to college. Maria indicated:

My grades had been good at the community college, not all A's but it wasn't impossible to do. The classes at HSU were pretty much the same, I mean the assignments and tests were not much harder than the classes I had at the community college. The community college let me know that I could be successful in college.... if I had not gone to the community college and had just started working I doubt that I would have ever completed my bachelor's degree. 


\section{The heating up path}

Participants who followed the heating up path also enrolled at a community college in a career field, with all indicating that they did not plan on earning a baccalaureate degree. Similar to those following the career path, six of the seven participants referenced a high school teacher or a supervisor or coworker at a part-time or summer job as influencing their decision to pursue postsecondary education. The participants in the heating up path differ from those in the career path as they did not "stop out" of postsecondary education, but maintained continuous enrollment as they moved from the community college to HSU.

Each individual following the heating up path indicated that encouragement from faculty or professional staff at the community college "heated up" their interest in continuing their education and served as the impetus to transfer to a four-year institution to complete a bachelor's in the career field. Juan told me:

I didn't even know that there was such a thing as a Bachelor of Applied Technology. I enrolled in the computer tech program at (name of Technical College) because of all the want ads I saw for (name of major computer manufacturer). One of my teachers kept telling me about the transfer program that HSU had worked out with them and I was making it in all the classes ... she gave my name to someone at HSU ... and they contacted me and helped with the transition.

Some heating up participants worked part-time after completing the community college credential. Selena shared:

Once I finished the associate's degree I was able to get a job at (name of employer). I had the choice of working part-time or fulltime for the same pay which was quite a bit more than I made at (name of fast food franchise). I decided to work part-time so that I could finish the degree faster. 
Other heating up participants worked full-time while finishing the baccalaureate degree. According to Bonita:

My community college advisor encouraged me to apply for a position at the child care center at HSU and to keep going for a bachelor's degree. I got the job and then I realized that she knew that finances were a major thing for me. The benefits that came with full-time employment made it possible for me to continue on. My daughter could attend the childcare center for a reduced rate and I was able to take one class free each semester as an employee of the university. When my daughter started all-day Kindergarten I was able to go full-time and now I am an elementary school teacher.

All of the participants following the heating up path utilized $2+2$ articulation agreements and completed an associate's degree prior to transfer to HSU.

\section{The traditional path}

Participants who followed the traditional path enrolled at a community college, completed an associate's degree in a transfer area, and then transferred to HSU to complete a bachelor's degree. Each of the traditional path participants indicated that they enrolled at a community college with the intent of completing a bachelor's degree. All of the traditional path participants referenced a family member as an influence in deciding to participate in postsecondary education, with four of six identifying an extended family member (e.g., cousin, aunt or uncle) who had previously attended college or earned a degree, rather than an immediate family member. Three traditional path participants also identified a high school teacher as influential in their enrollment at the community college.

Financial considerations were identified by all traditional path participants as a primary reason they entered postsecondary education at a community college. Irma, for example, stated that:

My family lives in (name of city) and so I started at (name of community college) because I could live at home and it wouldn't 
cost as much. I was able to go full-time and did two years there and then transferred here to complete my bachelor's degree.

The frequency of course offerings was identified by four of the six traditional path participants as a reason they entered postsecondary education at a community college. Bobby explained:

The community college has two locations and offers the same class multiple times during the day, in the evening and sometimes on the weekend. The university offers the same class multiple times, but often at 8, 9, and 10 in the mornings. I worked until 3 and realized that I would have more choices at the community college.

Three of the traditional path participants started at the community college, in part, because they were undecided about a major or program of study. Mary shared her experience:

I asked one of my high school teachers about going to college ... I had no idea about what I wanted to study, but I knew that I wanted a bachelor's degree ... She told me to start working for an associate's degree until I could decide on a major ... that I could save a lot of money by going to the community college. That is why I started at a community college ... to take general ed courses, save money, and decide on a major.

\section{The dual enrollment path}

Two participants were in a dual enrollment program with a community college during their junior and senior years of high school. This program allows students to take college-level courses and have them also count for high school credits. Courses are offered at the high school, but during the senior year, students can attend classes on the community college campus. Tuition is waived for all students admitted to the program, with each student responsible for a $\$ 5$ per-course records fee. Both dual path participants 
indicated that they planned on going to college and earning a bachelor's degree before they participated in the dual enrollment program. For Jacob, a high school teacher served as a key facilitator to his entry to the program:

Math always was easy and fun. I had a teacher in high school who suggested the dual credit program to me ... I suppose it was because I did so well in his math class. I trusted him and let him do whatever to get me in and I knew it didn't cost much at all. At the end of the semester, I got a grade report from the community college. Even my parents didn't completely understand at first, but they were very happy when they found out that I could take college classes for only $\$ 5$ during high school. So, I took more hours after that.

Jacob received a math scholarship to HSU. He enrolled at the community college for the summer session immediately after high school graduation and then completed the remaining requirements for the bachelor's degree at HSU.

Susan was well aware of the dual enrollment program and she completed 30 hours of college credit, the maximum possible.

The counselor gave me a brochure about the program and encouraged me to enroll. I took it home for my father to look at it. He checked the program out quite a bit and then told me that financially it made more sense for me to participate in this program and then get an associate's degree before my bachelor's degree.

After graduating from high school, she attended the community college on a full-time basis for an additional year, completing an associate's degree and then transferred to the university.

\section{Interpretative Analysis}

Interpretative analysis was conducted to search for possible explanations as to how the participants in this study began postsecondary education at a community college and persisted through the completion of a bachelor's 
degree. An initial question was whether the participants differed greatly from the literature that identifies characteristics that negatively impact or explain lower rates of degree completion (NCES, 2002; Swail et al., 2004).

Five of the personal characteristics that have been found to negatively impact baccalaureate completion among Latinos were shared in the participant narratives. All participants indicated that financial resources were the primary challenge to participating in postsecondary education. As a result, all participants worked while attending college, with 12 (46\%) reporting that they worked 35 hours a week (or more) during the entire time they were pursuing the degree. Twenty $(77 \%)$ were financially independent within three years of graduating high school and seven participants (27\%) shared that at some time during their pursuit of the bachelor's degree they were financially contributing to parents or other family members beyond their own household. Eleven (42\%) of the participants were married or had dependents during the time they were pursuing the baccalaureate, with three identifying as a single parent. Only two of the participants enrolled full-time (12 or more hours) each term while pursuing a bachelor's degree.

On the other hand, the participants did not report five other personal characteristics that have been found to negatively impact baccalaureate completion. The participants did not delay postsecondary participation as all but one enrolled immediately after completing high school or the GED. The participants did not earn alternative high school credentials as 25 of 26 completed a high school diploma. Parents of the participants had higher high school completion rates than national averages, as only two participants indicated a parent that had not completed high school. There was also a higher rate of postsecondary participation and completion among the immediate family members of the participants. Ten (38\%) participants reported that at least one of their parents had attended college and five (19\%) indicated that at least one parent had completed a bachelor's degree or higher. Three participants had older siblings who had participated in postsecondary education and earned some type of credential and only two indicated a sibling who had dropped out and never returned to postsecondary study.

The participants also did not report two of the three high school characteristics that have been offered as possible explanations for lower Latino completion rates. None of the participants were retained at the same grade level during their K-12 years and only four participants reported receiving a high school grade of $\mathrm{C}$ or lower. Attending multiple high schools was not 
common, as 24 of the 26 participants attended only one high school. The one high school characteristic found to be a negative impact on bachelor's degree completion reported by a number of the participants in this study was enrolling in lower-level math courses. Slightly less than half (12) of the participants tested into developmental math courses at the community college.

High school characteristics that have been found to increase the likelihood of baccalaureate completion were not reported by the participants of this study. Twelve (46\%) participants believed that the high school curriculum adequately prepared them for postsecondary education, but no one indicated the perception that they had completed a "rigorous" high school program. Only five (19\%) indicated the aspiration to attend college in the $10^{\text {th }}$ grade or earlier.

Continuous enrollment, an academic factor that has been found to significantly increase the likelihood of Hispanics obtaining a bachelor's degree, was common among the participants of this study. Only one participant was not continuously enrolled while pursuing their degree. The career path participants did stop out for a period of time and entered the workforce. After returning to postsecondary study, however, all attended continuously until completing the bachelor's degree. Among all other participants, the only person that did not maintain continuous enrollment stopped out for a spring semester and summer term.

\section{Considering the previous literature}

The interpretative analysis provides additional insight into three findings from the literature. Almost $70 \%$ of the participants of this study enrolled at the community college for employment purposes, either to secure a job or to increase earnings through additional training. Time and again, participants following the career and heating up paths referenced teachers in the junior and senior year of high school or employers and supervisors as individuals who initially encouraged them to consider the community college. In virtually every instance these experiences occurred during or after the $10^{\text {th }}$ grade. In addition, some of the participants who followed the heating up path were not aware of applied or technical baccalaureate degrees until they were enrolled at the community college. Arbona and Nora (2007) found aspiration to attend college before the $10^{\text {th }}$ grade as a precollege factor 
that increases the likelihood of Hispanics completing a bachelor's degree. In simple terms, many of the participants in this study did not have role models or academic or work experiences to develop such aspirations until after the $10^{\text {th }}$ grade. The timing of academic and career experiences influenced when many participants following these two respective paths initially aspired to attend college or to earn a bachelor's degree.

Arbona and Nora (2007) reference Fry (2002) in identifying full-time, continuous enrollment as an academic factor that increases the likelihood of completing a baccalaureate degree. In neither instance do the authors elaborate on the term continuous, whether it means fall and spring semesters or year-round enrollment. Year-round enrollment was a common practice among the participants in this study-fall and spring semesters as well as summer terms. All of the 26 participants attended year-round at least once while pursuing a bachelor's degree. When asked whether they enrolled full- or part-time, several participants questioned why full-time enrollment was measured on a semester to semester basis rather than on a complete calendar year. Most often participants described their enrollment patterns not as part-time, but as half-time (6 hours) or three-quarter time (9 hours).

The previous literature focuses on the education of parents and siblings in areas such as high school completion, college attendance and degree completion, and siblings who may have dropped out as possible explanations of lower completion rates of Latinos. As previously noted 10 participants reported parents who attended college, with 5 indicating a parent had earned the baccalaureate or higher. Three had an older sibling who had participated and earned some type of credential. Latino culture, however, often considers the extended family. When asked about family members who had attended college, seven participants who did not have parents or siblings with postsecondary experiences reported extended family members who had attended college with four of these individuals completing a bachelor's degree or higher. In other words, $35 \%$ of the participants in this study came from families where an immediate or extended family member had completed the bachelor's degree.

\section{Understanding participant success}

The interpretative approach also provided insight into perceptions of how the participants described their persistence to completion of the bachelor's 
degree. The participants were unanimous that continuous enrollment was a key factor in their successful completion of the baccalaureate. As indicated above, the overwhelming majority of participants in this study enrolled part-time and attended year-round. The primary reason given for part-time attendance was to allow for more hours to work, important to funding their education as well as to other financial responsibilities. Family responsibilities were also frequently identified as a reason for part-time attendance. Enrolling in three terms a year (fall, spring, and summer) was identified as the primary solution to attending part-time. As mentioned earlier, several participants questioned why full- and part-time designation was based on semester rather than yearly enrollment.

Eighteen participants in this study enrolled in postsecondary education to improve their economic futures. Sixteen (88\%) of the career and heating up participants indicated that the initial credentials earned at the community college allowed them to obtain employment at a higher wage. This additional income was instrumental in meeting both educational and family financial considerations and in persisting on the path to the baccalaureate.

Avalos, Briggs, \& Martinez (2017) point to a consumer approach to participation in higher education, where enrollment patterns include concurrent enrollment at multiple institutions, reverse transfer, and attendance at multiple two- and four-year institutions. Such patterns were not found among the participants of this study. The limited number of postsecondary institutions in the geographical area might be one explanation. The participants in this study attended three community colleges, all within an hour of HSU. None of the participants attended a four-year institution other than HSU. The common enrollment pattern among the participants in this study was more similar to a traditional $2+2$ transfer path, with 23 of the 26 participants completing an associate's degree. Each of these 23 participants indicated they were guided by either the articulation agreements between the two-year institutions and HSU or course by course transfer information that was readily available online. Following the recommended sequence of courses and affirming that all courses counted towards program and degree requirements were identified as keys to continued persistence and degree completion.

Interpretative analysis identified three additional factors contributing to persistence to the bachelor's degree that contributes to understanding the experiences of the overwhelming majority of the participants in this 
study. A supportive network is the term I use in interpreting comments from $22(85 \%)$ of the participants regarding how they were able to persist to completion of the bachelor's degree. The narratives describing the respective paths point to the importance of different categories of people in these networks. High school teachers and counselors, employers and supervisors, co-workers, and community college faculty and advisors were referenced frequently as influencers on the decision to enroll in postsecondary education or to return or continue towards the baccalaureate. The participants also indicated that they remained in contact with the initial influencers, who most often became supporters after they enrolled, and as they persisted to degree completion. Immediate or extended family members were identified as supporters and family with previous higher education experience served as valuable sources of the academic capital necessary to understand the complexities of higher education and navigate along their respective paths. Peers also contributed to support networks as those who were further ahead in completing the bachelor's degree served as mentors and provided suggestions from their experiences and others served as partners, taking classes together, studying together, and sharing notes from missed classes. Each of these 22 participants indicated that without a supportive network they were doubtful that they would have completed the bachelor's degree.

I use the term proactive to scheduling life in interpreting comments from $21(81 \%)$ of the participants regarding how they were able to persist to completion of the bachelor's degree. The common illustration of being proactive was knowing when course schedules for the next semester would be released. Early consideration of the course schedules allowed the participants to not only plan for class attendance but to plan for life by addressing any conflicts with work or family responsibilities. Proactive also included enrolling during pre-enrollment periods before classes might fill up, applying for financial aid before priority deadlines, scheduling meetings with advisors or other professional staff well in advance of any deadlines, and not procrastinating on class readings or assignments. Participants who were parents indicated the importance of not always scheduling classes or work during school or childcare hours, sharing that keeping some of this time for studying was a key factor in persisting to degree completion.

The term education as a priority stemmed from my interpretation of comments from 19 (73\%) of the participants regarding how they were able 
to persist to completion of the bachelor's degree. Many of these individuals reflected on "first" experiences that made them realize that postsecondary education had become a priority in their life, and often was the top priority. These experiences included the first time they chose to attend class rather than skip and the first time they told friends "no" to an evening out to stay home to study. Delaying significant financial decisions to afford tuition and noneducational costs, such as moving to a larger apartment, purchasing a new car, or taking a vacation were also identified as key points where participants realized the priority they were placing on completing the degree.

\section{Conclusions}

A fundamental question is whether "beginning at the community college" provides a clear description of the path taken by Latina/o students who complete a bachelor's degree. The findings of this study suggest that at HSU it does not. The Latino participants in this study followed multiple paths in attaining the bachelor's degree. Their experiences are not sufficiently explained by simply indicating that the community college was the entry point to postsecondary education. Adelman (2006) has stressed the importance of understanding the complexities of enrollment patterns for all students. From the experiences of the participants in this study, four different paths to the baccalaureate emerged that began with enrollment at a community college.

Previous studies have pointed to the low baccalaureate completion rates found among Latinos who began postsecondary education at a community college, and have questioned the viability of a community college path to the baccalaureate (Arbona \& Nora, 2007; Fry, 2002; Swail et al., 2005). Overwhelmingly comparisons have used outcomes such as six-year graduation rates and semester to semester full-time enrollment. From the perspective of the participants in this study, the community college facilitated, rather than inhibited baccalaureate attainment. Eighteen of the 26 participants followed the career or heating up paths, indicating that they did not enter postsecondary education with the intent to earn a bachelor's degree. The confidence gained in their academic abilities while attending the community college and encouragement from community college faculty and professional staff were key factors in their decisions to continue past an initial 
credential or associate's degree and persist to completion of a bachelor's degree. Participants following the career and heating-up paths also stressed that this initial experience with postsecondary education enabled them to secure better-paying jobs, thus providing sufficient financial resources for them to continue their enrollment or return later to pursue the degree. The role of the community college in the baccalaureate paths of the overwhelming majority of participants in this study follows what Adelman (2006) termed purposeful transfer as 23 of the 26 participants completed the associate's degree and referenced articulation agreements and transfer guides as important resources that facilitated completion of the bachelor's degree.

There are a number of limitations to this study. Participants volunteered to be interviewed and are not a representative sample of all graduates at HSU. In addition, aspects of the community colleges or HSU may have influenced the experiences of the participants. There are a significant number of Latinos at HSU as well as the community colleges that the participants attended, in faculty and administrative positions and within the student population. Having numerous potential role models and opportunities for formal and informal mentoring may have contributed to the academic success of the participants in this study. Laden (1992) found that organizational culture contributed to the transfer rate of Latino students at a California community college. The knowledge and importance of articulation agreements and the online transfer guide suggest that the organizational culture at the community colleges and HSU may have contributed to the retention and degree completion of the Latinos in this study.

Although it is not possible to generalize, a basic finding of this study is that the backgrounds and characteristics of the participants both conflict with and support the literature on negative impacts to or explanations of lower rates of Latina/o baccalaureate completion. Participants also do not universally demonstrate all of the characteristics that have been found to increase the likelihood of Latinos earning a bachelor's degree. In other words, the success of the participants in this study cannot be explained by deficit measures that focus on "why not".

How did these Latina/o students complete the baccalaureate degree? Due to economic constraints or family responsibilities, the overwhelming majority of Latino graduates in this study were not able to attend college on a full-time basis. Almost 70\% enrolled in a community college with no aspiration to the bachelor's degree and $42 \%$ stopped out to work for a period 
of time. Year-round enrollment, attending each term, was the common strategy to address part-time attendance and also allowed for additional time to work to meet financial challenges or to attend to parenting or other family responsibilities. Individuals who did enter for economic reasons found that their initial education and training provided higher paying positions that helped provide the financial resources necessary to continue beyond the associate's degree. A more traditional, 2+2 pattern of enrollment was followed, with articulation agreements and an online transfer guide serving as valuable resources in identifying the academic path to the baccalaureate.

Three factors drawn from the participant narratives explain their perception of "how" they persisted to complete the bachelor's degree. A supportive network of individuals encouraged and championed the educational goal of the participants, from initial interest through enrollment to persistence and finally degree completion. As a whole, the participants of this study came from families with parents who had higher high school and baccalaureate completion rates higher than the national Hispanic average and combined with the educational experiences and success of extended family were an important part of this network. High school teachers and guidance counselors, community college faculty and professional staff, employers and supervisors, co-workers, and peers pursuing degrees were also referenced multiple times as critical members of support networks.

Participants perceived that taking a proactive approach to scheduling life; their academic, work and personal lives was essential to successful progress towards and ultimate completion of the degree. There was a keen understanding of the importance of continuous enrollment and the importance of proactive scheduling to ensure that work and family responsibilities did not stop the individuals from continuing on their paths. The participants also indicated a point of self-realization that, for them, education had become an important priority. This self-realization served as an internal influence towards realizing the goal of the bachelor's degree.

\section{Recommendations}

Considering the time enrolled and excluding the stop out time in the career path, nine of the participants completed the bachelor's degree in six 
years-both participants following the dual path, five participants following the traditional path, and two participants following the heating up path. Eleven participants completed the bachelor's degree within eight years-the final traditional path participant, four participants following the heating up path, and six career path participants. Realizing the number of participants who enrolled in fewer than 12 hours a semester and the year-round enrollment pattern, an eight-year degree completion period is a logical time frame.

For the participants in this study, completing a minimum of $15 \mathrm{credit}$ hours a year in continuous year-round enrollment is the common factor explaining "how" they navigated four distinct paths to the bachelor's degree. HSU should consider including this outcome measure in reporting persistence and graduation rates. In addition, articulation agreements and an online transfer guide were identified as important resources used by the participants. Identifying how these materials were discovered, and efforts to provide this information to additional numbers of Latina/o students is recommended as a possible strategy to further improve completion rates. As mentioned previously, participants in this study do not represent the entire population of HSU graduates. Additional research would be warranted to determine the extent the findings of this study represent all HSU grads.

Educational leaders are encouraged to conduct studies of the paths that Latino graduates have followed at their respective institutions to better understand factors that facilitate baccalaureate completion. Examinations of the types of institutions attended, the sequences of attendance, and how these paths developed and were navigated will add further to efforts to improve Latino completion rates. Through understanding additional stories of success, educational leaders can identify outcome measures that are more representative of the growing numbers of Latina/o students participating in postsecondary education.

\section{References}

Abrica, E.J. (2018). How to measure student success? Toward consideration of student resilience as a metric of success in institutional accountability frameworks. Community College Journal of Research and Practice, DOI: 10.1080/10668926.2018.1429962 
Adelman, C. (2006). The toolbox revisited: Paths to degree completion from high school through college. Washington, DC: U.S. Department of Education.

Arbona, C., \& Nora, A. (2007). The influence of academic and environmental factors on Hispanic college degree attainment. The Review of Higher Education, 30, 247-269.

Avalos, S., Briggs, K., \& Martinez, M. (2017, September). The winding road: How today's student consumes higher education. Academic Advising Today, 40(3). Retrieved from https://www.nacada.ksu.edu/Resources/AcademicAdvising-Today/View-Articles/The-Winding-Road-How-Todays-StudentConsumes-Higher-Education.aspx

Bauman, K. (2017, August 28). School enrollment of the Hispanic population: Two decades of growth. Retrieved from https://www.census.gov/ newsroom/blogs/randomsamplings/2017/o8/school_enrollmentof.html

Berg, B.L. (2004). Qualitative research methods for the social sciences, Fifth edition. Boston, MA: Pearson.

Bogdan, R.C., \& Biklen, S.K. (2003). Qualitative research for education: An introduction to theory and methods, Fourth edition. Boston, MA: Pearson.

Contreras, F. (2015, October). The education landscape of Latino students in the Central San Joaquin Valley \& California. Commissioned Paper California Latino Leadership Education Summit. Retrieved from http:// www.fresnostate.edu/president/documents/Education-Landscape.pdf

Crisp, G., \& Nora, A. (2010). Hispanic student success: Factors influencing the persistence and transfer decisions of Latino community college students enrolled in developmental education. Research in Higher Education, 51, 175-194.

Fry, R. (2002). Latinos in higher education: Many enroll, too few graduate. Retrieved from https://www.pewhispanic.org/2002/o9/05/latinos-inhigher-education/

Fry, R. (2003). Hispanics in college: Participations and degree attainment. ERIC Digest. New York: Teachers College, Columbia University, ERIC Clearinghouse on Urban Education. (ERIC Document Reproduction Service No. ED 480917)

Fry, R. (2004). Latino youth finishing college: The role of selective pathways. Retrieved from https://www.pewhispanic.org/2004/06/23/latino-youthfinishing-college/

Harper, S. R. (2010). An anti-deficit achievement framework for research on 
students of color in STEM. In S. R. Harper \& C. B. Newman (Eds.), Students of color in STEM: Engineering a new research agenda. New Directions for Institutional Research (pp. 63-74). San Francisco: Jossey-Bass.

Heller, J. (2006, Aug). Using "path dependency" as a method in historical research. Paper presented at the annual meeting of the American Sociological Association, Montreal, Quebec, Canada. Retrieved from http:// research.allacademic.com/index.php?click_key $=1 \&$ PHPSESSID $=8$ vu1md6b 1elegb3mk6mpgpfkp3

Hoachlander, G., Sikora, A.C., Horn, L., \& Carroll, C.D. (2003). Community college students: Goals, academic preparation, and outcomes (NCES 2003164). Washington, DC: U.S. Department of Education, National Center for Education Statistics.

Laden, B. V. (1992, October). An exploratory examination of organizational factors leading to transfer of Hispanic students: A case study. Paper presented at the annual meeting of the Association for the Study of Higher Education, Minneapolis, MN. (ERIC Document Reproduction Service No. ED 352922).

Laden, B.V. (2001). Hispanic-serving institutions: Myths and realities. Peabody Journal of Education, 76, 73-92.

Lee, V.E., Mackie-Lewis, C., \& Marks, H. (1993). Persistence to the baccalaureate degree for students who transfer from community college. American Journal of Education, 102(1), 80-114.

Marrón, A.A., \& Luna, G. (2019). Motivating factors for Latinas earning a family studies baccalaureate degree at a university extended campus. Journal of Hispanic Higher Education, 18, 77-97.

Merriam, S. B. (Ed.) (2002). Qualitative research in practice: Examples for discussion and analysis. San Francisco, CA: Jossey-Bass.

National Center for Education Statistics. (2002). Profile of Undergraduates in U.S. Postsecondary institutions: 1999-200o. NCES 2002-168. Washington, DC: U.S. Department of Education. (ERIC Document Reproduction Service No. ED 468124).

Nuñez, A.M., Sparks, P. J., \& Hernandez, E. A. (2011). Latino access to community colleges and Hispanic-Serving Institutions: A national study. Journal of Hispanic Higher Education, 10, 18-40.

Oseguera, L., Locks, A.M., \& Vega, I.I. (2009). Increasing Latina/o students' baccalaureate attainment: A focus on retention. Journal of Hispanic Higher Education, 8, 23-53. 
Page, S.E. (2006). Path dependence. Quarterly Journal of Political Science, 1, 87-115.

Pierson, P. (2004). Politics in time: History, institutions, and social analysis. Princeton, NJ: Princeton University Press.

Rendon, L.I., \& Nora, A. (1989). A synthesis and application of research on Hispanic students in community colleges. Community College Review, 17, 17-24.

Reyes, N.A.S., \& Nora, A. (2012, July) Lost among the data: A review of Latino first generation college students. White paper prepared for the Hispanic Association of Colleges and Universities. Retrieved from https://www. hacu.net/images/hacu/OPAI/H3ERC/2012_papers/Reyes\%2onora\%20 -\%20rev\%2oof\%201st\%2ogen $\%$ 2olatino\%2ocollege $\%$ 2ostudents $\% 20$ -\%202012.pdf

Ryan, C. L., \& Bauman, K. (2016, March). Educational attainment in the United States: 2015. Washington DC: United States Census Bureau. Retrieved from https://www.census.gov/content/dam/Census/library/publications/2016/ demo/p20-578.pdf

Sáenz, V. B., García-Louis, C., Drake, A. P. \& Guida, T. (2018). Leveraging their family capital: How Latino males successfully navigate the community college. Community College Review, 46, 40-61.

Sáenz, V.B., Mayo, J.R., Miller, R.A., Rodriguez, S.L. (2015). (Re)defining masculinity through peer interactions: Latino men in Texas community colleges. Journal of Student Affairs Research and Practice, 52, 164-175.

Shapiro, D., Dundar, A., Huie, F., Wakhungu, P., Yuan, X., Nathan, A \& Hwang, Y., A. (2017, April). Completing College: A National View of Student Attainment Rates by Race and Ethnicity - Fall 2010 Cohort (Signature Report No. 12b). Herndon, VA: National Student Clearinghouse Research Center.

Swail, W. S., Cabrera, A. F., \& Lee. C. (2004). Latino youth and the pathway to college. Retrieved from https://www.pewhispanic.org/2004/06/23/ latino-youth-and-the-pathway-to-college/

Swail, W. S., Cabrera, A. F., Lee. C., \& Williams, A. (2005). Latino students and the educational pipeline. Part III: Pathways to the bachelor's degree for Latino students. Retrieved from https://files.eric.ed.gov/fulltext/ ED485304.pdf 